\title{
New Zealand's tobacco control programme 1985-1998
}

\author{
Murray Laugesen, Boyd Swinburn
}

\begin{abstract}
Objective-To review the impact of New Zealand's tobacco control programme from 1985 to 1998 on smoking prevalence and tobacco consumption, and to estimate the scope for further reduction.

Design-Country case study; interventions, with outcomes ranked internationally across time.

Setting-New Zealand 1985-98; for 198595, 23 OECD countries.

Interventions-Between 1985 and 1998, New Zealand eliminated tobacco advertising, halved the affordability of cigarettes, and reduced smoke exposure in work time by $39 \%$.
\end{abstract}

Main outcome measure-Reduction in adult smoking prevalence and in tobacco products consumption per adult.

Results-Changes in prevalence 1985-98: in adults (aged 15+ years), $-17 \%$ (from $30 \%$ to $25 \%$ ) but short of the $20 \%$ target for 2000; in youth (aged 15-24 years), $-20 \%$ (from $35 \%$ to $28 \%$ ); and in Maori adults (aged $15+$ years), $-17 \%$ (from $56 \%$ in 1981 to $46 \%$ in 1996). Changes in consumption 1985-98: tobacco products per adult aged $15+$ years, $-45 \%$ (2493 to 1377 cigarette equivalents); cigarettes smoked per smoker, $-34 \%$ (22.7 to 15.0 per day). Between 1985 and 1995 New Zealand reduced tobacco products consumption per adult more rapidly than any other OECD country, and reduced youth prevalence more rapidly than most. The acceleration of the decline in cigarette attributable mortality rates in men and in women age 35-69 years averted an additional 1400 deaths between 1985 and 1996. Between 1981 and 1996 smoking prevalence among blue collar workers decreased only marginally, and in 14-15 year olds, rose by one third between 1992 and 1997.

Conclusion-In 13 years, New Zealand's tobacco control programme has been successful in almost halving tobacco products consumption, particularly by lowering consumption per smoker. With strong political support for quit campaigns, increased taxation, and the elimination of displays of tobacco products on sale, the consumption could theoretically be halved again in as little as 3-6 years.

(Tobacco Control 2000;9:155-162)

Keywords: New Zealand, tobacco control policy; Organisation for Economic Cooperation and Development
This paper reviews New Zealand's national tobacco control programme (TCP), asking whether it has: (1) fulfilled its original aims and targets in reducing smoking; (2) achieved reductions in smoking among youth, Maori, and lower income groups; (3) reduced exposure to second hand smoke; (4) reduced cigarette mortality; and (5) made favourable progress compared to other OECD (Organisation for Economic Cooperation and Development) countries.

This review begins in 1985, when the Minister of Health publicised a "comprehensive policy to promote non-smoking" from his advisory committee on smoking and health, which asked the government to commit itself to its TCP plan. The plan included public involvement and health education, quit clinics for adults, restricted adolescent access to tobacco products, regulation of tar yields, increased taxation, smokefree environments, health warnings, and a ban on advertising tobacco products and on tobacco brand name sponsorships. ${ }^{1}$

At the 1996 census, the overall smoking prevalence for adults (aged 15+ years) was $23.7 \%$. For Europeans the prevalence was $23 \%$, for Pacific people $32 \%$, and for Maori $46 \%$. Maori, who are the indigenous people of New Zealand, comprised $11.7 \%$ of the total adult population but $22 \%$ of the adult smoking population.

In this review we have attempted to assess the impact of the total TCP because, apart from sharp increases in tobacco tax, a single component usually cannot be studied in isolation from the total programme. We also assessed the scope for the TCP to achieve further reductions in smoking and mortality.

\section{Methods}

POPULATIONS AGED 15 YEARS AND OVER

(1) New Zealand mean resident total population 1985-98 (supplied by Statistics New Zealand 1999).

(2) Maori in New Zealand 1981-96, adjusting for the changed census definitions of Maori. ${ }^{2}$

(3) The 23 OECD countries as at January 1995, after deleting Mexico because of lack of data, were: Australia, Austria, Belgium, Canada, Denmark, Finland, France, Germany, Greece, Iceland, Ireland, Italy, Japan, Netherlands, New Zealand, Norway, Portugal, Spain, Sweden, Switzerland, Turkey, UK, USA, excluding Luxembourg. Federal Republic of Germany data were used for Germany

Health New Zealand,
and Heart Foundation,
Auckland
M Laugesen
B Swinburn
Correspondence to:
Dr Murray Laugesen, Health
New Zealand, PO Box 360
Waiheke, New Zealand;
laugesen@healthnz.co.nz
Received 23 July 1999 and in
revised form
October 18, 1999. Accepted
9 November 1999 
pre-1990. Population data were from published WHO/OECD/UN midyear estimates.

(4) Comparisons of mortality: OECD countries were compared on 1990 mortality. Iceland and Turkey were deleted because of lack of data, and Luxembourg included. ${ }^{3}$ Maori mortality was based on 1989-93. ${ }^{2}$

(5) Prevalence and cigarettes per day (cpd): data were obtained from 21 OECD countries (table 1).

(6) For the existence of smokefree legislation: 1996 data. $^{4}$

DATA SOURCES

For total population and Maori, the census gave smoking prevalence data for 1976, 1981, and 1996. For the total population, a continuous doorstep survey of 10000 persons gave prevalence since $1982 .^{5}$ OECD data for 1985-95 were obtained from the Health New Zealand database. ${ }^{6}$ The data are based on statistical yearbooks, official reports, and web sites.

\section{MEASUREMENTS}

(i) Consumption of tobacco products per adult per year (hereafter called consumption)-This is a summary measure of smoking and was calculated as the annual volume sales of tobacco products (derived from tobacco taxes paid) per adult aged $15+$ years, measured in cigarettes, or in the case of roll your own (RYO) tobacco, in grams. The traditional approximation of $1 \mathrm{~g}$ of tobacco being equivalent to one cigarette was used in the absence of data on the weight of tobacco per manufactured cigarette by country and year.

(ii) Weight of tobacco in tobacco products-This allows for the fact that tobacco weight per manufactured cigarette was less than $1 \mathrm{~g}$ and varied by year. For other tobacco products, tobacco weight was calculated as equalling the product weight.

(iii) Smoking prevalence-In New Zealand, this was defined as the percentage of adults aged 15 years and over who smoked manufactured or hand rolled cigarettes. In other countries, smoking prevalence definitions varied, and their inclusion of cigar and pipe smoking may have given New Zealand an artificially lower prevalence than a few other countries, but would not have affected comparisons based on the rate of prevalence reduction. (iv) Cigarettes per day (cpd)-This was calculated from the formula $\mathrm{cpd}=($ (i) above $) /$ [((iii) above $) \times 365]$. This avoids the under reporting inherent in self reported cpd data. (v) Addiction - This was measured as the time from waking to first cigarette.

(vi) Costliness and its inverse, affordabilityWithin New Zealand, costliness was estimated from the time taken to earn 20 cigarettes at the average hourly ordinary time earnings before income tax. For international comparisons, costliness was defined as the percentage of per capita gross domestic product (GDP) required to buy 20 cigarettes every day.

CALCULATION OF AVERTED MORTALITY

Cigarette smoking attributable mortality ignored deaths: Under the age of 35 years (for example, from sudden infant death syndrome), from smoking only pipes or cigars, and from passive smoking in never smokers. It was calculated by Peto's indirect method, from the second American Cancer Society study (ACS-II) cohort study. He attributed lung cancer to smoking according to the difference between the national rate and the ACS-II non-smokers' rate. He then calibrated the severity of the epidemic in each country and year against the ACS lung cancer rate benchmark. ${ }^{3}$ For other diseases he conservatively attributed to smoking only half the smokers' excess mortality. The seven, five year age specific rates were averaged to give the 35-69 years age standardised rate.

The rate decreases in age standardised, cigarette attributable mortality between its 1975 peak in men, or its 1985 peak in women, and the respective 1996 rate, were applied to the 1995 population to estimate the number of cigarette deaths of each sex averted in 1996. The TCP's effect was calculated from the acceleration in those rate decreases after 1985 in the 35-79 year old population.

ASSUMPTIONS FOR FURTHER REDUCTION IN CONSUMPTION WITHIN 3-6 YEARS

Policy 1-An Australian style quit campaign could be expected to reduce tobacco products consumption per adult by at least $10 \%$ if sustained for 3-6 years, based on the fact that in only six months, the 1997 Australian campaign reduced prevalence and consumption per adult by $4-5 \%$, by inducing quitting. ${ }^{7}$ In addition, a media campaign was expected, while it lasted, to double smokers' reported temporary quit episodes, from 2 to 4 weeks per

Table 1 New Zealand trends in tobacco and tobacco products consumption and adult and youth smoking prevalence, with OECD rankings for 1995 values and rate of change 1985-95

\begin{tabular}{|c|c|c|c|c|c|c|}
\hline & 1985 & 1990 & 1995 & $\begin{array}{l}1995 \text { OECD rank } \\
(1 \text { st }=\text { lowest })\end{array}$ & $\begin{array}{l}1985-95 \% \\
\text { change }\end{array}$ & $\begin{array}{l}\text { OECD rank for rate of } \\
\text { change } 1985-95\end{array}$ \\
\hline $\begin{array}{l}\text { Tobacco products/adult, consumption, cigarettes or grams } \\
\text { RYO per adult per year }\end{array}$ & 2493 & 1959 & 1472 & 2 nd of 23 & $-41 \%$ & 1 st of $23^{\star}$ countriest \\
\hline Cigarettes or grams RYO/ smoker/ day & 23 & 20 & 15 & 2 nd of 21 & $-34 \%$ & 1 st of $21 \ddagger$ \\
\hline Adult smoking prevalence age $15+$ years $(\%)$ & 30 & 27 & 26 & 8 th of 21 & $-12 \%$ & 9 th of $21 \ddagger$ \\
\hline Youth smoking prevalence $15-24$ years (\%) & 35 & 32 & 29 & 10th of 19 & $-18 \%$ & 3rd of $17 \ddagger$ \\
\hline
\end{tabular}

$\star 1$ st $=$ largest reduction achieved of any country in group.

†Data on tobacco products consumption per adult: 23 OECD countries compared (see Method).

$\ddagger$ Data on smoking prevalences and consumption per smoker, 1995: not obtained for Switzerland; Turkey; for youth prevalence not for Belgium, Denmark, Greece, Japan, Switzerland, Turkey. Netherlands data were for ages 15-19 years. In a few years, prevalences were estimated from adjacent year values.

Source: Health New Zealand database $1999,{ }^{6}$ based on national statistical publications, US Department of Agriculture, ${ }^{46}$ UN commodity production and trade data, and OECD mid year populations, including cigarettes by number, cigars, and manufactured tobacco (including RYO and pipe) by weight, calculated as: 1 manufactured cigarette $=1 \mathrm{~g}$ tobacco. Smokeless tobacco was not included. RYO, roll your own. 
year, and thus depress consumption by a further $4 \%{ }^{8}$

Policy 2-A tax increase of 50 cents per pack of 20 in May 1998 increased cigarette prices 13\% and decreased consumption by $10.2 \%$ over the following 12 months. ${ }^{9}$ Similarly, a 50 cents per pack tax increase in 1991 increased the price by $17 \%$ and decreased sales by $15 \%$. We estimate that if the tax was increased sufficiently to cause a $50 \%$ increase in price from the current (year to June 1999) average of $\mathrm{NZ} \$ 6.50$ (US\$3.40) to NZ\$9.75 (\$US5.10), it would lower cpd and consumption per adult by $44 \%$ below the 1998 level. Such a fall would be permanent because the tobacco tax rate per gram of tobacco is adjusted regularly for inflation, and is uniform across tobacco products.

Policy 3-The effect of not permitting display of tobacco products for sale is difficult to estimate, but according to a cigarette company marketing manager, display is essential for maximising sales. ${ }^{10}$ Making advertising bans total but permitting display has been estimated to lower consumption $6 \% .{ }^{11}$ The effectiveness of bans increase as they become more complete. ${ }^{6}$ If the bans were extended to ban display of tobacco products, we estimated a further one step decrease of $1-2 \%$ with permanent effect.

Policies (1) to (3) above, assuming they acted without overlap or synergy, could together lower consumption $50 \%$. Given sufficient political will, 3-6 years may still be needed to increase the tax in stages.

ESTIMATION OF THE EFFECT OF REDUCED SMOKING ON MORTALITY.

We focused only on the three policy effects above. The estimated fractional reductions, when multiplied together, would halve the 1998 consumption per adult. A number of assumptions and calculations were used in deriving these estimates. We ignored averted deaths in those under 35 or over 70 years of age. The 1996 population aged 35-69 years was projected 16.5 years using life table methods, based on 1995 mortality rates by age and sex. The 1995 non-cigarette attributable mortality rates by age and sex were calculated by Peto's method ${ }^{3}$ and applied to the 1996 census never-smoker population by age and sex to estimate survival and mortality risk within the next 16.5 years. The total mortality risks within 16.5 years for never, heavy (21+ cpd), light (1-20 cpd), and ex-smokers by age and sex were obtained from the ACSII study, ${ }^{12}$ and calibrated according to the New Zealand never smoker population mortality risk. Based on the 1981-96 decreases (tobacco products consumption $-48 \%$, prevalence $-26 \%$, and cpd $-30 \%{ }^{9}$ ), we calculated the deaths averted if $26 \%$ of smokers quit (reducing prevalence from $25 \%$ in $1998^{9}$ to $18.5 \%$ ) and if continuing smokers reduced cpd by $30 \%$, from $15 \mathrm{cpd}$ (recorded in $1998^{\circ}$ ) to $10.5 \mathrm{cpd}$.

\section{Interventions}

PUBLIC INVOLVEMENT THROUGH INFORMATION AND EDUCATION

Public education was mainly through news items, mandated health warnings on tobacco packets, and paid advertising campaigns. News items in newspapers on smoking issues averaged 4000 annually from 1986-91, but fell to between 2000 and 2900 annually during 1992-98. Estimated from newspapers' own files, and from purchased news items, ${ }^{13}$ the peak years (5000 items) were 1986 (Smokefree Week) and 1990 (legislation). The number of weekly news items was associated with lower cigarette sales. ${ }^{14}$ The public debate of the issues created informed support for the policies needed to reduce smoking. The media were supplied with views from a variety of organisations, in particular: the Tobacco Institute of New Zealand from 1980; ASH (Action on Smoking and Health) from 1983; the Department of Health (subsequently the Ministry of Health) from 1985 which reported to the public from its monitoring programme ${ }^{9} 15-17$; the Coalition to End Tobacco Advertising during 1989-1993; the Smokefree Coalition from 1995; the crown public health units from 1996; and the Maori smokefree coalition (ATAK) from 1998.

\section{ADULT ORIENTED PROGRAMMES}

Paid advertising campaigns lasted only a few weeks each because of the costs involved. About $\$ 1.5$ million (1995 NZ\$) was spent on the Smokefree Week (1986) and "Kick it in the Butt" (1988-90). After that (1991-98) there was no major campaign or public service announcements targeting adult smoking. Three health groups began a quit campaign in one region in late 1998 (using Australian advertisements "Every cigarette is doing you damage"). Pharmaceutical companies advertised nicotine replacement therapy in the 1990s. Quit clinics were not seen as cost effective. ${ }^{18}$ In 1998 not one quit clinic was in operation.

\section{YOUTH ORIENTED PROGRAMMES}

Despite in-class education, half of 14-15 year olds in 1993 said they had received no information from school about smoking in the past year. ${ }^{19}$ The government ran media campaigns discouraging adolescent smoking in 1979, 1984, and latterly, at NZ\$1 million annually, in 1996-99 ("Why Start?"). The Smoke-free Environments (SFE) Act 1990 established a Health Sponsorship Council, funded from the health budget, to promote health through sponsorship and to replace tobacco sponsorship advertising of arts, culture, and sports for a 2-3 year period after the end of tobacco sponsorships. It also used its discretionary funds to promote its main brand, "Smokefree", paying particular attention to sponsoring school based events, minor sports, and sports favoured by high smoking prevalence groups. Government separately allocated half a million dollars a year for smokefree schools programmes from 1996.

In 1986 an amendment to the Toxic Substances Act 1979 banned trade in oral tobacco, (smokeless tobacco) and another in April 1988 banned tobacco product sales to under 16 year olds. The SFE Act incorporated these bans, and also banned the giving of 
tobacco product samples by the tobacco trade. From July 1997 the minimum age at which people could be sold tobacco products was raised to 18 years and more responsibility was placed on the retailer. From February 1998, cigarette packs of less than 20 cigarettes and tobacco packs of less than $30 \mathrm{~g}$ were banned.

From 1996 to 1999 the Ministry of Health was allocated nearly NZ\$1 million annually for enforcement, mainly to stop underage sales, as detected by under age volunteers. ${ }^{20}$ In 1996-97 volunteers aged on average 14.5 years were sold cigarettes on $15 \%$ of shop visits; in 199798, and again in 1998-99, on 5\% of visits. From 1996-99, an average $10 \%$ of retailers were visited annually, and some $4 \%$ of all visited were successfully prosecuted for selling to under age persons. ${ }^{21}$ Surveys of $14-15$ year old smokers found that personal buying of cigarettes decreased from $60 \%$ in 1992 to $38 \%$ in 1997; someone else buying for them increased from $14 \%$ in 1992 to $46 \%$ in 1997 ; and supply from family increased from $14 \%$ to $25 \%$. In $1992,25 \%$ reported being refused sale because of their age, with $62 \%$ reporting refusal in 1997. In 1992, 7\% reported difficulty buying cigarettes compared to $28 \%$ in $1997 .{ }^{22}$

REGULATION OF PRODUCT CONTENT

The SFE Act required manufacturers to report annually to the Ministry of Health the tar and nicotine yields in the smoke of all manufactured cigarette brands sold, as well as the amount of tobacco, additives, and price. The Act provides the Director General of Health with the powers to require manufacturers to pay for additional independent testing. The Ministry of Health adopted a harm reduction approach for tobacco products, ${ }^{23}$ and in 1997 Parliament amended the SFE Act to enable tighter regulation of harmful constituents, but to date, such regulations have not been prepared. In 1998, many cigarette brands had higher smoke yields of $\operatorname{tar}^{24}$ than would have been permitted in the European Union. In 1998, RYO and non-filter cigarettes, which have higher tar yields, comprised over $20 \%$ of all tobacco smoked.

TAXATION

The 1985 TCP aimed to "adopt a taxation policy that encourages non-smoking". ${ }^{1}$ From 1986 to 1992 the economic recession provided an important incentive to maximise tobacco tax revenue and this coincided with health objectives. The affordability of cigarettes halved between 1985 and 1998, with the number of minutes needed to earn 20 cigarettes ${ }^{25}$ increasing from 12 (1985), to 22 (1995), and to 24 minutes (late 1998). Tax rates were significantly raised in real terms in 1986, 1988, 1989, 1991, and 1998. From 1990 onwards tobacco tax was adjusted for inflation at least annually. Tax rates per 1000 cigarettes or per kilogram of tobacco were equalised across tobacco product types based on their tobacco weight (1995). In December 1998, the tobacco excise was 19.3 cents (10 cents US) per cigarette ( $59 \%$ of the average price) and the goods and services tax was another 3.6 cents (11\% of the price). In 1985, New Zealand was ranked 10 th among OECD countries for the costliness of cigarettes but by 1990 it was second and in 1995 it was third. The 1995 price of $20 \mathrm{cpd}$ (every day $)^{26}$ equalled $9 \%$ of per capita gross domestic product (GDP) in Ireland, $8 \%$ in the UK, $7 \%$ in New Zealand, and less in other OECD countries.

RESTRICTIONS ON SMOKING

The 1985 TCP aimed to promote smokefree enclosed public and workplaces. The SFE Act 1990 banned smoking on most public transport, in half of restaurant seating, in shared offices, in the public parts of workplaces including shops and banks, and in most enclosed public places. In 1997, the amended Act required $25 \%$ of casino gaming floors to be smokefree. Other authorities such as airports and shopping malls and many schools have since enforced their own extended smokefree zones. The Act did not protect factory workers, nightclub, bar, and casino workers from second hand smoke. Public support ensured compliance in office workplaces but restaurant smokefree zones were often ignored; by 1998 only one case had come to court.

REQUIREMENTS FOR WARNINGS

Government and manufacturers agreed on weak cigarette packet warnings- "Smoking may damage your health" (1974-80), then "Smoking can endanger your health" (1980-88). From mid-1988, under regulatory threat, stronger warnings appeared on all tobacco packets except cigars. Regulations under the SFE Act 1990 required cigarettes and cigarette tobacco to carry these warnings: "Smoking causes lung cancer", "Smoking causes heart disease", "Smoking causes fatal diseases", "Smoking damages your lungs"; it also required pipe tobacco and cigars to carry the message "Smoking causes lung cancer". Stronger warnings were sought by the government in 1994 but tobacco industry objections successfully slowed the passage of regulations, delaying the stronger warnings until 2000.

TOBACCO ADVERTISING RESTRICTIONS

Broadcast authorities stopped tobacco advertising on television and radio in 1963. Government and manufacturers in 1973 agreed to ban tobacco advertising on cinema screens and outdoor billboards. Tobacco advertising otherwise continued with minimal restrictions, under government industry agreements signed in 1973, 1979, 1985, and 1987.

The 1985 TCP forecast was "1990: as public support builds up, amend (the) law to ban advertising and sports sponsorship." The Act banned new tobacco advertising from December 1990 by print media and shops signs, and banned new sponsorships. However, manufacturers used a legislative loophole to display in-shop "price notices" resembling advertisements. During the $1995-98$ period, manufacturers agreed to limit price notices to one square metre per shop. The SFE Act, amended in 1997, made the ban total, restricting price notices to business card size from December 
1998. Product displays were permitted. Only Norway, Tasmania, and perhaps one or two other jurisdictions have such extensive advertising bans.

The 1990 "World Cup cricket amendment" gave the Minister of Health power to grant exemptions to the sponsorship ban, but few were granted, and none after 1996. A proposed 1991 amendment would have repealed the tobacco sponsorship ban, but all parties agreed in 1993 to postpone the commencement of the ban from 1993 to July 1995. The "Winfield amendment" permitted tobacco sponsored rugby league until December 1995.

Advertising of tobacco brand names on other goods was also banned by the SFE Act (1990), with qualified exceptions for goods that had been on sale before the Act, such as Dunhill watches. Selling tobacco brand named items such as clothing or coffee became illegal.

\section{Main outcome measures}

The 1985 TCP paper set a target of reducing smoking prevalence in adults to $20 \%,{ }^{1}$ without specifying a time limit. From 1994 the Public Health Commission ${ }^{27}$ and then the Ministry of Health adopted this target for completion by 2000 , and a consumption target of 1000 cigarettes per adult by 2000 .

\section{Results}

SMOKING PREVALENCE OUTCOMES

Adult prevalence

The population reduced its smoking prevalence from $36 \%$ in 1976 to $32 \%$ in 1981 , then to $24 \%$ in 1996 (using census data); and (using annual survey data) from $30 \%$ in 1985 when the TCP began, to $25 \%$ in $1998^{\circ}$-halfway towards the target of $20 \%$ prevalence by 2000 . Adult smoking prevalence in 1995 was eighth lowest among 21 countries.

\section{Youth and teenage prevalence}

Smoking prevalence in youth (aged 15-24 years) decreased $20 \%$ (from $35 \%$ in 1985 to $28 \%$ in 1998). Of 17 countries, New Zealand had the third most rapid reduction of youth smoking prevalence between 1985 and 1995 (table 1). Daily prevalence at age 15-19 years fell $39 \%$ (from $31 \%$ in 1985 to $19 \%$ in $1998 .^{5}$ ) Daily prevalence at age $14-15$ years rose $37 \%$ (from $11.6 \%$ in 1992 to $15.5 \%$ in 1997 ). ${ }^{28}$

\section{Maori prevalence}

Maori prevalence between 1981 and 1996 decreased by $18 \%$ (from $56 \%$ to $46 \%$ ) using the 1981 definition of Maori. ${ }^{2}$ In terms of percentage points, this 10 point reduction compares with an 8 point reduction for the total population over the same period. ${ }^{29}$ In 1996, Maori had twice the smoking prevalence of the total population, ${ }^{30}$ starting smoking earlier $^{30}$ and continuing longer. ${ }^{30}$ Among ever smokers, $29 \%$ of Maori had quit, as against $48 \%$ in the total population. ${ }^{29}$ Interestingly, Maori had similar attitudes to smokefree issues, ${ }^{31}$ similar addiction and quit attempt rates, ${ }^{8}$ and were equally frequent users of the Quitline $^{32}$ compared to the total population.
Socioeconomic status (SES) prevalence

The medical profession reduced its smoking prevalence early, from $35 \%$ (1963) to $20 \%$ (1976) to $15 \%(1981)$ to $5 \%(1996) .{ }^{33}$ This two thirds reduction in smoking prevalence among doctors between 1981 and 1996 was high compared to other occupational classes. Professionals in total reduced their prevalence by one third (from $23 \%$ to $16 \%$ ), and technical and other professionals class reduced prevalence by $29 \%$ (from $41 \%$ to $29 \%$ ). Only minor prevalence changes (between $-6 \%$ and $+0.8 \%$ ) were recorded for the managerial class ( $29 \%$ to $27 \%$ ), clerks ( $30 \%$ to $28 \%$ ), service and sales workers ( $36 \%$ to $35 \%$ ), trades workers $(35 \%$ to $36 \%)$, and labourers $(49 \%$ to $49 \%) .^{34}$ In 1992-93, those of below average socioeconomic status consumed three quarters of all tobacco (products). ${ }^{35}$

CONSUMPTION PER ADULT OUTCOMES

Trends and targets

From 1975 to 1985, consumption (tobacco products consumption per adult) decreased $23 \%$, accelerating to a $41 \%$ decrease in 1985-95 under the TCP. The compound annual rate of decrease in consumption averaged $-4.7 \%$ between 1985 and 1990, $-5.6 \%$ between 1990 and $1995,-0.8 \%$ between 1995 and 1998, then accelerating after the May 1998 tobacco tax increase.

Over this review period between 1985 and 1998, consumption decreased by $45 \%$, from 2493 to 1377 cigarettes per adult per year in $1998-75 \%$ of the distance to the 1000 target set for the year 2000. Tobacco weight consumed per adult - a measure not specified in the targets-decreased $48 \%$ from $2149 \mathrm{~g}$ in 1985 to $1118 \mathrm{~g}$ in 1998.

\section{Rate of reduction}

On tobacco products consumption per adult, New Zealand had the most rapid reduction of smoking of any OECD country between 1985 and 1995 (table 1). Between 1981 and 1996, consumption fell $48 \%$ in New Zealand as a whole, ${ }^{9} 41 \%$ in Canada, $40 \%$ in Australia, and $38 \%$ among Maori in New Zealand. ${ }^{2}$ Twenty OECD countries experienced lower percentage decreases than Maori.

\section{Consumption level}

In 1995, New Zealand's tobacco products consumption was second lowest of the OECD countries, with only Sweden's consumption being lower (table 1). The 1998 level at 1371 cigarettes per adult was the lowest since records began in 1920. In comparison with the US states, New Zealand in 1995 appeared to rank among the lowest four states for consumption, after allowing for RYO tobacco. ${ }^{4}$

CONSUMPTION PER SMOKER OUTCOMES

In $1998,78 \%$ of tobacco used was in manufactured cigarettes, $21 \%$ in RYO, and $1 \%$ in pipe and cigar tobacco. ${ }^{24}$ Between 1985 and 1998, cpd per smoker decreased by 34\% (22.7 to $15.0 \mathrm{cpd}$ ). Between 1981 and 1996, cpd for Maori decreased 25\% (23.0 to $17.3 \mathrm{cpd}$ ) as against a $28 \%$ fall (24.8 to $17.4 \mathrm{cpd}$ ) in the 
total population. ${ }^{2}$ In 1995 , Norway had a lower cpd but New Zealand's rate of reduction in cpd was the most rapid of 21 countries (table 1 ).

\section{SMOKEFREE LIFESTYLE OUTCOMES}

At work

In $1989,31 \%$ of workers were exposed to second hand smoke while working ${ }^{8}$ (as opposed to tea breaks), decreasing after the SFE Act to $21 \%$ in 1991 , and to $19 \%$ in $1996 .{ }^{8}$ California, Norway, ${ }^{36}$ and Sweden ${ }^{37}$ banned smoking at work, along with various US and Canadian cities.

\section{Eating out}

In $1998,50 \%$ of restaurant seating was mandated smokefree, but bars carried no restriction. In 1998, California banned smoking in both restaurants and stand alone bars, while Utah, ${ }^{5}$ Norway, ${ }^{36}$ Western Australia, South Australia, and the Australian capital territory had $100 \%$ smokefree dining laws.

\section{At home}

Of $14-15$ year olds, $39 \%$ were exposed to second hand smoke in $1989,33 \%$ in $1991,{ }^{38}$ and $38 \%$ and $39 \%$ in 1997 , of whom one third were exposed to two parents' smoke. ${ }^{39}$

CIGARETTE MORTALITY OUTCOMES

In 1995,4800 deaths ( $17 \%$ of all deaths) were attributed to cigarettes. In 1989-93 Maori deaths comprised nearly $10 \%$ of these, accounting for $31 \%$ of all Maori deaths. ${ }^{2}$

\section{Deaths averted}

The estimated deaths from smoking at age 35-79, which were averted between 1985 and 1996 because of the declines in smoking since 1975, were about 12000 for men and about 200 for women, whose mortality rates have only decreased recently. In the absence of further declines in smoking from 1985, the smoking attributable deaths for 35-79 year old men in 1996 would have been about 3500 instead of the 2200 they actually were. For women aged 35-79 years, if 1985 smoking attributable mortality rates had applied in 1996, smoking attributable deaths would have been 1300 , as against 1200 estimated. Three quarters of the male averted and $60 \%$ of the female averted deaths were age 35-69 years, each such middle aged death on average averting 22 years of life otherwise lost. $^{3}$

Cigarette attributable mortality trends

Middle aged (35-69 years) cigarette attributable male mortality peaked around 1975 at 1917 deaths (table 2). The rate fell rapidly (37\% decline) between 1985 and 1996 from about 1666 to 1200 deaths (3.67 to 2.31 per 1000 per year). The cigarette attributable deaths and mortality rate for middle aged women peaked around 1985 at 663 deaths. The rate fell $10 \%$ from 1.35 per 1000 in 1985 to 1.21 per 1000 in 1996 (626 deaths).

\section{Acceleration in the decline in cigarette mortality rate}

Cigarette deaths averted per year in middle aged men rose from 650 in 1985 to 938 in 1996, totalling 9600 averted deaths in middle aged men from 1985 to 1996 . The annual rate of decline in the cigarette attributable death rate accelerated $21 \%$ between $1975-85$ and 1985-96.

\section{Lung cancer rate trends}

Mortality rates in New Zealand men (aged 35-69 years) decreased from 1975 (1.16 per 1000,491 deaths) onwards. Lung cancer has begun to decrease among women born after 1940. Among New Zealand women aged 35-54 years, lung cancer mortality rates decreased from 12 per 100000 (67 deaths) in 1991 to 7 per 100000 (46 deaths) in $1995 .{ }^{40}$ In women overall, the lung cancer rate increased little from 1990-96. ${ }^{9}$ Lung cancer killed Maori at three to four times the rate of the total population. ${ }^{2}$ Cigarette attributable cancer rates in middle age decreased in Maori men between 1984-88 and 1989-93, but continued to increase in Maori women. ${ }^{2}$

\section{Lung cancer rate comparisons}

Lung cancer mortality rates in middle aged New Zealand men ranked sixth lowest of 22 countries whereas middle aged women ranked fifth highest. ${ }^{3}$ Middle aged women in New Zealand had a $51 \%$ higher lung cancer mortality rate than in Australia in 1995, ${ }^{41}{ }^{42}$ despite almost identical female smoking prevalence rates since $1976 .{ }^{43}$ In $1989-93$, the lung cancer mortality rates for middle aged Maori men and women ${ }^{2}$ were respectively higher than in either sex of 22 OECD countries in 1990, except for Belgian males. $^{3}$

CAPACITY TO REDUCE SMOKING FURTHER We estimate the potential reductions in consumption achievable within 3-6 years if there is sufficiently strong political support for the following three policies: (1) mass media quit campaigns modelled on the Australian campaign and sustained for three years should induce long term quitting (tobacco products consumption $-10 \%)$ and increase short term quitting (-4\%) across all SES groups; (2) stepwise tobacco tax increases can achieve a 50\% increase in the price of cigarettes (estimated

Table 2 Mortality, whether cigarette smoking attributable or not, in New Zealand in middle age (age 35-69 years), 1975 to 1996, annual rates per 1000 persons, age standardised

\begin{tabular}{|c|c|c|c|c|c|c|}
\hline Death rates per 1000 (mean of seven age specific rates, age 35-69 years) & 1975 & 1985 & 1990 & 1995 & 1996 & $1985-96 \%$ change \\
\hline Male, cigarette smoking attributable & 4.57 & 3.67 & 2.89 & 2.41 & 2.31 & $-37 \%$ \\
\hline Male, all other mortality & 9.48 & 8.21 & 7.16 & 6.57 & 6.53 & $-21 \%$ \\
\hline Female, cigarette attributable & 1.01 & 1.35 & 1.33 & 1.28 & 1.21 & $-10 \%$ \\
\hline Female, all other mortality & 6.50 & 5.42 & 5.01 & 4.45 & 4.34 & $-20 \%$ \\
\hline
\end{tabular}

Source: Peto $e t a l^{\beta}$ for 1975-90; 1995-96 data calculated by same method. 
$44 \%$ reduction in tobacco products consumption); (3) non-display of tobacco products in shops (estimated $1-2 \%$ decrease in consumption).

The multiplied effect of these policies (assuming no overlap or synergy) would be to reduce consumption by about $50 \%$. Once consumption halves, we estimate that over 2000 deaths can be prevented before age 70 , during the first 16 years.

\section{Discussion}

This review of New Zealand's TCP shows that, despite not attaining its original prevalence target, the TCP has fulfilled many of its original aims and has successfully reduced smoking since 1985. Smoking rates in adolescents, Maori, and those of low socioeconomic status, while remaining high, have also reduced over this time period. Exposure to second hand smoke at work has also reduced. Cigarette attributable mortality has declined significantly for males including Maori, and is declining in women under 70 years in the total population, though not for Maori.

The level of TCP activity has been highly dependent on the prevailing political will and was closely correlated to changes in smoking prevalence. Activity was highest in 1984-90, culminating in the SFE Act. A new government in 1990 wanted initially to repeal the tobacco sponsorship ban; and did not fund any media quit campaign from 1991-98, but instead began a campaign in 1996 to prevent adolescents from starting to smoke. Adult prevalence fell from $27 \%$ in 1990 to $26 \%$ in 1991 (owing to a tax increase), rose to $27 \%$ during $1991-94,{ }^{4}$ a period of little political commitment to TCP, fell to $26 \%$ during 1995 98 , and fell again to $25 \%$ in 1998 following a tax increase. ${ }^{32}$

The medical profession led the reduction in smoking by example in the 1960 s, but little happened in the wider population until the 1980 s when major health groups funded ASH to publicise and politicise the issue. The new government welcomed the 1985 TCP initiative. Health groups formed coalitions at critical periods. The committed health bureaucracy, and the absence of a large tobacco growing and manufacturing industry, also assisted. A single legislature, a slow rate of GDP growth to fuel demand for consumer products such as cigarettes, and a government often needing taxation revenue, also helped.

The reductions in smoking compare favourably with other OECD countries, and by most measures New Zealand appears to have achieved the greatest percentage reduction in tobacco products consumption over the 1985-95 decade. New Zealand's tobacco taxation policies increased government revenue and reduced consumption. Decreased affordability could also help explain the relatively rapid reduction of youth smoking prevalence as the decision to smoke can be price sensitive. ${ }^{44}$

Despite these gains, major concerns still remain about New Zealand's TCP. Smoking prevalence among 14-15 year olds recently increased. The causes of this are not apparent and clearly warrant more attention. Adult smoking prevalence has not decreased as rapidly as in other countries, consistent with the more recent lack of political will for the TCP and the absence until recently of a media led quit campaign. California has decreased its prevalence to $18 \%$ through a range of strong tobacco control policies and, similarly, the Australian prevalence has now fallen to $22 \%{ }^{7}$ As prevalence decreases, it is possible that the remaining smokers are the more heavily addicted ones and this might make further reductions in prevalence difficult. ${ }^{45}$ European and white collar smokers, however, with half the prevalence rates of Maori and blue collar workers, had similar addiction levels. ${ }^{8}$ While not discounting the hypothesis completely, it does suggest that the prevalence rates could be reduced substantially without encountering any great increase in nicotine induced resistance to quitting.

Smoking in several groups, particularly lower SES groups, has decreased little if at all and therefore strategies which are particularly effective in lower income groups need to be used preferentially. Tax increases and media led quit campaigns are good examples of strategies which should reach lower SES groups effectively, if not preferentially. The continued high smoking rates among Maori is of major concern and interventions to reduce these rates need to be kept a high priority. Cigarette attributed cancer is still rising in Maori women of middle age, and the higher rate of lung cancer in New Zealand women compared to Australian women of middle age is consistent with high female smoking prevalence from a young age.

\section{Conclusion}

New Zealand's TCP has been successful by OECD standards in reducing smoking rates. The TCP, however, needs to be broadened in scope and better resourced to lower smoking and smoking attributable morbidity and mortality further. The key to achieving this is political will. Government commitment is needed to strengthen the taxation, legislation, and regulation strategies as well as to provide adequate resources for quit campaigns to assist Maori and low SES smokers in particular. The comprehensive tobacco control policy now needs updating for 2000 to 2005. Given sufficient political commitment to the above strategies, it appears possible that tobacco consumption could be halved over the next 3-6 years.

The authors acknowledge financial assistance from the Ministry of Health in researching this paper, but the views expressed are entirely those of the authors.

1 Advisory Committee on Smoking and Health. Comprehensive policy for the promotion of non-smoking in New Zealand. Wellington: Department of Health, 1985.

2 Laugesen M, Clements M. Cigarette smoking mortality among Maori 1954-2028. Wellington: Te Puni Kokiri (Ministry of Maori Development), 1998.

3 Peto R, Lopez AD, Boreham J, Thun M, Jr CH. Mortality from smoking in developed countries 1950-2000. Oxford: Oxford University Press, 1994.

4 Office of Smoking and Health. CDC's tobacco information - state and national tobacco control highlights, California. Atlanta: Centers for Disease Control. lights, California. Atlanta: Centers for
www.cdc.gov/nccdphp/osh/statehi/, 1999. 
5 AC Nielsen (formerly OTR Spectrum Research). Cigarette smoking surveys. Wellington: Ministry of Health, 19821999.

6 Saffer H, Chaloupka F. Tobacco advertising: economic theory and international evidence. Working paper 6958. Cambridge, Massachusetts: National Bureau of Economic Research, 1999.<http://www.nber.org/papers/w6958>

7 National Tobacco Campaign. Australia's national tobacco campaign, vol 1. Canberra: Department of Health and Aged Care, 1999

8 National Research Bureau. Environmental tobacco smoke study. Wellington: Ministry of Health, 1996.

9 Ministry of Health. Tobacco facts. Wellington: Ministry of Health, 1999. <www.moh.govt.nz>

10 Glaser N. Tobacco continues downward trend. Retail Today 1999;April:15-17.

11 World Bank. Curbing the epidemic: governments and the economics of tobacco control. Washington: World Bank, 1999.

12 US Department of Health and Human Services. The health benefits of smoking cessation. A report of the Surgeon General, benefits of smoking cessation. A report of the Surgeon General, for Disease Control, Office on Smoking and Health, 1990. for Disease Control, Office on Smoking and

13 ASH New Zealand. Records of Chong Press Clippings Bureau newsclips, 1988-99. Auckland: ASH NZ, 1999.

14 Laugesen M, Meads C. Advertising, price, income and publicity effects on weekly cigarette sales in New Zealand supermarkets. Br $\mathcal{F}$ Addiction 1991;86:83-9.

15 Laugesen M. Tobacco control: 10000 deaths averted and greater gains possible. NZ Public Health Rep 1995;2:89-91

16 Slama K, ed. New Zealand's monitoring system for tobacco control 1984-1992. Ninth World Conference on Tobacco and Health, 1994. Paris. Plenum Press, 1995.

17 Anon. Progress on health outcome targets. Wellington: Ministry of Health, 1993-98.

18 Chapman S. Stop-smoking clinics: a case for their abandonment. Lancet 1985;i:918-20.

19 McGee R, Williams S, Stanton W. Smoking among New Zealand adolescents. NZ Med F 1995; 108:85-7.

20 Price L, Allen $M$. Enforcing the law on tobacco sales to minors. NZ Public Health Report 1998;5:9-10.

21 Hon Tuariki Delamere, Associate Minister of Health. Sales of cigarettes to minors slashed. Media release. 11 Octobe 1999 .

22 Laugesen $M$, Scragg R. Changes in cigarette purchasing by fourth-form students in New Zealand 1992-1997. NZ Med $\mathcal{F}$ In press.

23 Ministry of Health. National drug policy part I: tobacco and alcohol. Wellington: Ministry of Health, 1996

24 Laugesen $M$. Tobacco consumption resumes downward trend. NZ Public Health Rep In pres

25 Laugesen M. Tobacco statistics 1996. Wellington: Cancer Society of New Zealand and Ministry of Health, 1996.

26 Non-Smokers' Rights Association. Average retail selling price and total tax incidence for a pack of 20 cigarettes in
various countries as of March 22, 1995. Ottawa: Non-Smokers' Rights Association, 1995.
27 Public Health Commission. Tobacco products. Wellington: Public Health Commission, 1994.

28 Laugesen M, Scragg R. Trends in cigarette smoking in fourth-form students in New Zealand, 1992-1997. NZ Med F 1999;112:308-11.

29 Anon. Census of population and dwellings, smoking prevalence data. Wellington: Statistics New Zealand, 1996.

30 Ministry of Health. Taking the pulse (New Zealand Health Survey 1996-7). Wellington: Ministry of Health, 1999.

31 CM Research. Public opinion survey of smokers' attitudes. Wellington: Health Sponsorship Council, 1999

32 Delamere T. Delamere delighted with fall-off in smokingmedia release. Office of the Associate Minister of Health 1999, 31 May 1999

33 Hay DR. Cigarette smoking by New Zealand doctors and nurses: results from

34 Narugopal Pal. Smoking prevalence and trends in New Zealand by occupational status. Health Funding Authority special report 2. Wellington: Health Funding Authority, 1998.

35 Whitlock G, MacMahon S, Hoorn SV, et al. Socioeconomic distribution of smoking in a population of 10529 New distribution of smoking in a population

36 Anon. Norway, Law no 10, 17 February 1995 . International Digest of Health Legislation 1995;46:192-3.

37 Anon. Sweden, Law 98 of 17 March 1994. International Digest of Health Legislation 1995;46:62.

38 National Research Bureau. Monitor of smoking behaviour amongst NZ Teenagers (second reading). Wellington: Department of Health, 1991

39 Laugesen M. ASH national survey of smoking among fourth formers 1997. Report to the Ministry of Health. Wellington: Ministry of Health, 1998.

40 Laugesen $M$, Fraser J. Lung cancer rate falling in women aged 25-54 years [letter]. NZ Med F 1998;111:350-1.

41 NZ Health Information Service. Mortality and demographic data 1953-95. Wellington: Department of Health/Ministry of Health, 1954-98.

42 Australian Institute of Health and Welfare (AIHW). Cancer in Australia 1995: incidence and mortality data for 1995 and in Australia 1995: incidence and mortality data for 1995 and selected data for 1996. AIHW catalogue number
(Cancer Series no10). Canberra: AIHW, 1998 .

43 Winstanley M, Woodward S, Walker N. Tobacco in Australia. Facts and issues 1995, 2nd ed. Melbourne: Victorian Smoking and Health Program, 1995.<www.quit.org.au>

44 US Department of Health and Human Services. Preventing tobacco use among young people. A report of the Surgeon General, 1994. Atlanta, Georgia: Public Health Service, Centers for Disease Control and Prevention, Office on Smoking and Health, 1994. (US Government Printing Office Publication No S/N 017-001-00491-0.)

45 Fagerstrom KO, Kunze M, Schoberberger R, et al. Nicotine dependence versus smoking prevalence: comparisons among countries and categories of smokers. Tobacco Control 1996;5:52-6.

46 US Department of Agriculture. <www.fas.usda.gov/ tobacco/circular> 